\title{
História, ciência, e sociedade em Fausto Cardoso
}

\author{
History, science, and society in Fausto Cardoso
}

Piero Detoni a

E-mail: pierodetoni@gmail.com https://orcid.org/0000-0002-5106-7868 iD

a Universidade de São Paulo, Faculdade de Filosofia, Letras e Ciências Humanas, Departamento de História, São Paulo, SP, Brasil 


\section{RESUMO}

O presente artigo apresenta a série de artigos "A ciência da história", material publicado por Fausto Cardoso na Revista Brasileira, no decorrer do ano de 1895. Objetiva-se colocar em evidência a sua reflexão acerca dos fundamentos da prática científica, bem como do estatuto científico da história. É nossa pretensão contextualizar os escritos de Cardoso junto aos horizontes do cientificismo brasileiro. Tomamos as suas reflexões como indícios das transformações pelas quais o contexto epistêmico-historiográfico das décadas finais do século XIX atravessou. Ao estudarmos os artigos do intelectual sergipano, temos a possibilidade, ainda, de reelaborar a memória disciplinar da história da historiografia brasileira, que por muito tempo sustentou que o seu foco de análise era o progresso da pesquisa histórica científica. Assim sendo, os textos de Fausto Cardoso mostram-se úteis para intensificarmos a descrição dos planos de historicidade que envolvem as formas possíveis de legitimação da disciplina história em nosso país.

\section{PALAVRAS-CHAVE}

Cientificismo. Epistemologia. Historiografia brasileira.

\section{ABSTRACT}

This article presents a series of articles entitled "A ciência da história", published by Fausto Cardoso in the Revista Brasileira in 1895. With that, we aim to highlight his thoughts on the foundations of scientific practice and the scientific status of History contextualized within the horizons of Brazilian scientism. The author's reflections are taken as evidence of the transformations in the epistemic-historiographical context of the final decades of the $19^{\text {th }}$ century. His articles also enable us to rework the disciplinary memory of the history of Brazilian historiography, which has long focused on analyzing the progress of scientific historical research. Thus, the work of Fausto Cardoso proved useful for intensifying the description of historic plans involving possible forms of legitimizing history teaching in our country.

\section{KEYWORDS}

Scientism. Epistemology. Brazilian historiography. 


\section{Uma breve reabilitaçāo da posiçāo intelectual de Fausto Cardoso}

Ao menos desde a criação do Instituto Histórico e Geográfico Brasileiro, em 1838, percebemos um paulatino processo de disciplinarização da história como conhecimento no Brasil, em um movimento descontínuo e conflitante que pretendeu torná-la uma prática dita científica. Durante a segunda metade do século XIX, sobretudo, a partir da recepção das teorias sociais europeias pela geração de 1870 , verificamos várias proposições intelectuais nacionais que conferiam estatuto de ciência à atividade historiográfica. Não foram poucos os agentes sociais que almejaram transformar o saber histórico em um produto científico entre nós, acionando ideias de autores como Auguste Comte, Charles Darwin, Henry Thomas Buckle, Herbert Spencer, Ernst Haeckel, Friedrich Ratzel, Ernest Renan, Hippolyte Taine, Frédéric Le play, Vacher de Lapouge, entre outros. O movimento de transposição dos modelos explicativos elaborados por esses sujeitos, a maioria versada nas mais distintas matrizes das nascentes ciências sociais, da mesológica à biológica, junto à produção historiográfica brasileira é uma faceta daquilo que é denominado como cientificismo (WEHLING, 1994). Assim, as tentativas de tornar a história uma ciência fazem parte de uma discussão ampla travada, especialmente, entre intelectuais que circulavam naquele contexto, muitos deles presentes em centros de pesquisa e de ensino, como o IHGB, os museus etnográficos e as faculdade de direito e de medicina, situados no contexto de emergência e de consolidação da "moderna historiografia brasileira", entre as décadas de 1870 e 1920 (BRESCIANI, 2005).

Dessa forma, o que vemos nesse ambiente letrado é o cientificismo movimentar parte importante da intelligentsia nacional, envolvendo estudiosos como Tobias Barreto, Sílvio Romero, Fausto Cardoso, Ladislau Neto, Capistrano de Abreu, João Ribeiro, Rocha Pombo, Pedro Lessa, Felisbelo Freire, José Oiticica, Afonso Taunay, Oliveira Viana, entre outros. A matriz disciplinar (KUHN, 1975) cientificista anima as mais variadas contendas historiográficas. Todos esses autores citados, de um modo ou de outro, escreveram e teorizaram a partir da demandada dimensão científica da história. Cada um defendeu, a seu modo, uma ou outra corrente científica, divulgando e aplicando a teoria de um ou de outro pensador europeu em particular ou de forma cruzada. Desse modo, o mais perceptivo era o fenômeno do ecletismo, ou seja, uma disposição epistêmica em que havia imbricamento paradigmático. Nessa conversação disciplinar, os motivos historiográficos em circulação não possuíam razão em si mesmos. Assim, o cientificismo à brasileira não deve ser concebido a partir de uma recepção passiva daqueles ideários europeus considerados de vanguarda, o que retiraria todo o poder criativo dos agentes intelectuais brasileiros. Dito de outro modo: a mobilização de uma 
ou de outra teoria aplicada à história não significava a fé cega nos pensadores e nos cientistas europeus, havendo um importante processo de tradução e de apropriação (CHARTIER, 1990) diante dos problemas próprios da cena intelectual brasileira. Em resumo, o cientificismo brasileiro ganhava originalidade ante as suas matrizes europeias no processo de tradução e de conversão epistemológica, o que implicava no ecletismo e no processo de (re)formulação de teorias científicas cuja historicidade as tornava únicas.

Tendo em vista essas pressões epistêmico-contextuais, o foco analítico deste ensaio direciona-se para a leitura de "A ciência da história", sequência de artigos publicada na importante Revista Brasileira, no ano de 1895, pelo sergipano Fausto Cardoso. Há uma escassa produção acadêmica acerca tanto da biografia quanto do seu pensamento desse autor, sendo lembrado, via de regra, pela literatura memorialista e citado em alguns trabalhos que propõem balanços do estado da arte da filosofia e da sociologia, como no caso do conhecido texto de Antonio Candido sobre a história desta disciplina no Brasil (CANDIDO, 2006). Terezinha Oliva (1985), Giliard da Silva Prado (2009) e Mauro Franco Neto (2015) são os responsáveis pela sua reabilitação histórica. A primeira trabalha com a sua posição e militância política na Primeira República; o segundo com os significados da memória atrelados ao movimento político que lidera em Sergipe no ano de 1906; e o terceiro, em uma análise sintética, destaca o lugar da história em sua epistemologia. Mas parece ser uma questão a se considerar: qual o motivo do seu esquecimento pela história da historiografia brasileira? Lembrando que esse mesmo processo não ocorre com alguns dos seus contemporâneos de Escola de Recife, como é o caso de Tobias Barreto e de Sílvio Romero, que chegaram a conviver com Cardoso.

Redescrever a epistemologia da história elaborada por nosso autor significa, antes de qualquer coisa, uma aposta na socialização da atual comunidade de leitores de história com o passado da nossa disciplina (GOMES, 2000). Desconsiderar o conjunto de reflexões sobre a história elaborado por Fausto Cardoso só vem a reforçar certo cânone da história da historiografia brasileira que concebe o contexto socioepistêmico visível na Primeira República como um momento de passagem, muitas das vezes chamado de pré-modernista, em que se supervaloriza a historiografia de Capistrano de Abreu, bem como os chamados intérpretes do Brasil. Essa disposição mais encobre do que evidencia o processo epistemológico que resulta no saber histórico (WEHLING, 2006) elaborado pela "moderna historiografia brasileira". Para nós, o pensamento de Fausto Cardoso submerge diante de uma memória disciplinar que, a partir do momento em que é instituída, canoniza autores e obras em uma 
espécie de panteão dos nossos clássicos. Para Manoel Luiz Salgado Guimarães, "interrogá-lo é tarefa da historiografia, procurando deslindar as tramas que tornaram operatórias e necessárias estas escolhas, dentre um leque de outras possíveis" (GUIMARÃES, 2005, p. 32).

Fausto Cardoso é mais um bacharel em direito sergipano formado na Escola de Recife. Nasceu em 1864 na vila de Divina Pastora. Era filho de pais que compunham a elite aristocrata açucareira local. Na década de 1880, foi aprovado nos exames para o ingresso na muito citada e prestigiada Faculdade de Direito do Recife. Em Pernambuco, frequentou círculos literários e filosóficos que o introduziram junto ao estudo das principais matrizes do cientificismo. Voltou ao estado natal para ocupar o cargo de promotor público, mas, após desentendimentos com a política regional, mudou-se para o Rio de Janeiro, dedicando-se à advocacia, ao jornalismo e ao magistério. Cardoso era participante ativo nos movimentos republicano e abolicionista. Chegou a publicar o jornal Aurora, periódico adepto desse posicionamento político. Foi indicado pelo expresidente Prudente de Morais para deputado representante de Sergipe em 1900. Exerceu o cargo até 1902. Quatro anos depois foi reeleito, porém, esse foi o ano da sua morte. Ele se fez conhecido na capital federal através da sua oratória parlamentar contestatória em âmbito tanto regional quanto nacional. No ano de 1906, ao lado dos seus correligionários, preparou oficialmente um movimento de oposição às oligarquias sergipanas. Os "faustistas" organizaram uma revolta (que mais tarde veio a se chamar "Revolta de Fausto Cardoso") que, a princípio, saiu vitoriosa, mas que terminou a partir de uma reviravolta que expulsou Cardoso e os seus aliados do Palácio de Aracaju. Em meio à essas circunstâncias, o parlamentar foi assassinado com tiros de fuzil e de espingarda.

Quando Fausto Cardoso publicou a série de artigos "A ciência da história", em 1895, o bacharel republicano trazia consigo a experiência de ter lançado duas obras de maior fôlego, quais sejam, Cosmogenia política americana (1892) e Concepção monista do universo (1894). Nelas se vê o importante impacto em seu pensamento das ideias do biólogo alemão Ernst Haeckel. Sob essa influência, ele desenvolveu uma cosmogonia bastante particular. O nosso autor, antes de cair no esquecimento, ganhou espaço para a divulgação das suas teorias em um periódico destacado junto à intelectualidade finissecular: a Revista Brasileira. Para Moema Vergara, dentre os periódicos circulantes no período, ela "foi, sem dúvida alguma, uma importante 'vitrine' para literatos do período. Os seus vários tomos, de periodicidade quinzenal, formam um panorama da produção literária e cultural que procurava definir a identidade nacional" (VERGARA, 2004, p. 75). Na terceira fase da Revista (1895-1899), capitaneada por José Veríssimo, havia grande 
espaço para assuntos científicos, ou seja, se historicizarmos as contribuições de Cardoso no periódico em questão, solucionamos estas duas questões: 1) naquela época as suas contribuições foram publicadas em um periódico de prestígio e de ampla circulação ao menos acadêmica, quer dizer, um público intelectual considerável pôde ler os seus escritos; 2) se alinhamos o pensamento de Cardoso, apesar da sua originalidade, aos objetivos e ao escopo da Revista Brasileira, percebemos que ele não era um outsider em se tratando de proposição quanto ao caráter intrínseco das ciências.

As reflexões de Fausto Cardoso realizam-se como texto prescritivo, responsável, pois, por pensar propositivamente a epistemologia do conhecimento histórico, em seus escritos, entrevê estratégias discursivas segundo as quais o fazer e a escrita da história podem ou devem assumir. Ademais, esse tipo de modalidade textual é marcado tanto pela leitura crítica do pecúlio historiográfico disponível, quanto por indicações sobre os caminhos que a prática dos historiadores deve ou pode tomar em termos teóricos e instrumentais. Os artigos de "A ciência da história" se interessam, antes de tudo, pela dimensão em si da produção científica, ou seja, pelas suas condições de possibilidade como material intelectual que almeja a verdade certificada junto ao universo fenomênico. Após isso, são elaboradas questões voltadas especificamente para o campo historiográfico. É possível observar, por exemplo, estes problemas epistemológicos: qual o estatuto da história como conhecimento? Qual o caráter da sua produção até aquele dado momento? Pode-se falar em ciência da história? Qual a deontologia dos seus aportes teórico-metodológicos? Acreditamos que essas e outras questões são articuladas para reorientar o campo historiográfico desenvolvido até aquele dado momento, para imprimir ação disciplinar no presente e para nortear, como herança, as futuras pesquisas em história.

Diante disso, desenvolvemos alguns argumentos que explicam, mesmo que provisoriamente, o esquecimento de Fausto Cardoso junto às tradições de análise da história da historiografia brasileira: 1) o autor não fez parte, apesar de egresso da Escola de Recife, das instituições que consagravam os intelectuais brasileiros na passagem para o século $X X$, isto é, o IHGB e a $A B L ; 2$ ) a sua perspectiva monista, para o contexto em que é publicizada, retirava a legitimidade política da República Federativa. O seu monismo foi precursor da linguagem do "Brasil legal" e do "Brasil Real", que recrutou vários intelectuais autoritários na Primeira República (lembrando que, em 1902, ele lança o opúsculo Lei e arbítrio - discurso em defesa de uma ditadura parlamentar, pelo Congresso Nacional); 3) a memória da sua posição política radical, em que apareceu como líder de uma revolta, é contestada por seus algozes, resultando em um complexo jogo de lembrança e de esquecimento durante todo o século XX sergipano; 
4) o contexto pós-20 tornou inatuais as diversas matrizes de evolucionismos cosmogônicos (isso impactou o desenvolvimento da sociologia como saber, que se disciplinarizou à custa da superação do seu passado biologizante, como é o caso da teoria social movimentada por (ardoso); 5) por não considerar a história uma ciência, o autor foi "apagado" da suposta "evolução" da história da historiografia brasileira, que já celebrou os progressos da pesquisa histórica científica.

\section{A ciência é a fotografia das leis}

A produção historiográfica brasileira finissecular, ao menos no plano do discurso, distancia-se das práticas de marca romântica elaboradas pelas gerações que fundam o Império (NICOLAZZI, 2017). Isso ocorre, entre outras coisas, em virtude das importantes transformações na esfera pública nacional arregimentadas pela República (GOMES, 2009), as quais demandam do plano cultural novos protocolos, novas diretrizes, novas exigências e novos parâmetros, agora científicos, junto à produção de conhecimento. De acordo com os pesquisadores Mateus Pereira, Pedro Afonso dos Santos e Thiago Nicodemo:

as diferenças se colocam sobretudo em termos discursivos e geracionais: os historiadores formados no contexto de crise da Monarquia e nos primeiros anos republicanos procuravam se distanciar das gerações anteriores, mostrando-se atualizados nas discussões científicas típicas da Belle Époque (PEREIRA; SANTOS e NICODEMO, 2018, p. 41).

Mesmo que Fausto Cardoso não seja considerado um historiador stricto sensu, e que não considerasse a história como uma ciência per si, ele apresentou-se como um dos sujeitos mais interessados na sua conceituação como instrumento intelectual no contexto epistêmico da passagem para o século $X X$, bem como estava preocupado com o entendimento ontológico do processo histórico, posto que estabeleceu formas possíveis para a explicação do devir a partir de um complexo esquema evolucionista.

Para Fausto Cardoso, a ciência respeita, antes de tudo, princípios lógicos. A sua estruturação depende, então, de cinco premissas básicas: ela conforma um conjunto de orientações baseado em afirmações contundentes e verdadeiras; essas orientações circunscrevem um grupo específico de dados; as conclusões científicas possuem uma estrutura geral estável e um princípio capital; as suas apreciações são miméticas, ou seja, implicam na concordância exata entre o mundo objetivo e as formas de concebê- 
lo; a ciência, por fim, prefigura o universo experiencial. Partindo desses pressupostos, Cardoso estabelece o conteúdo do seu conceito de ciência: "o corpo de doutrina, o conjunto de princípios, a teoria que, em relação a um grupo determinado de fenômenos, é capaz de verificações e previsões certas e indubitáveis" (CARDOSO, 1895a, p. 238). A concepção de ciência ensejada por ele traduz, de uma forma que se quer exata, a empiricidade das coisas deste mundo. É uma ideia de ciência como adequação das formas. O seu pendor evolucionista possui a ambição de capturar os sentidos impressos no plano fenomenal.

A preocupação mais imediata de Fausto Cardoso é solucionar um problema de ordem epistemológica: o de como organizar uma teoria científica, sendo ela um espelhamento do universo empírico, diante de uma natureza estabelecida através da

pluralidade de fenômenos instáveis, móveis, variáveis, agitada, continua e eternamente em mil direções opostas, uma natureza, cujo aspecto muda em cada forma, em cada manifestação, sem unidade visível, sem corpo, conjunto monstruoso de elementos distintos, opostos, contraditórios (CARDOSO, 1895a, p. 239).

Em suma, o desafio da ciência, segundo a sua abordagem, é equalizar a mobilidade própria do devir, ante um processo intelectivo que torna os fenômenos da natureza, ou históricos, passíveis de serem apreendidos por uma grade de leitura que ressalta a imutabilidade, o fixo, as regularidades ou o permanente. Essa disposição podia ser resolvida através da mobilização de uma das disposições científicas mais acionadas nas décadas finais do século XIX, especialmente entre os bacharéis da Escola de Recife: o monismo formulado pelo biólogo alemão Ernst Haeckel. Foi através dessa importante fonte do cientificismo europeu recepcionada no contexto da geração de 1870 que Fausto Cardoso problematizou o impasse entre a fixidez dos quadros teórico-científicos e a mobilidade própria da realidade circundante. Isso a partir, claro, de uma leitura singular.

O crítico literário José Veríssimo, em sua póstuma História da Literatura Brasileira, vinda a lume em 1916, foi capaz de categorizar o movimento que oferece condições de possibilidade para reflexões como as prescritas em "A ciência da história". Veríssimo denomina esse contexto intelectual de modernismo, tendo em vista que ele não se reduz aos trânsitos da literatura, e também não emerge como escola literária, mas apresenta-se como um "movimento espiritual" que abrange "formas de pensamento" gerais, com impactos na política, na filosofia, nas artes e na ciência. Mesmo que enfatize a heterogeneidade do ideário modernista, o crítico estabelece que se norteia 
através do "pensamento filosófico e científico triunfante por meados do século XIX": o "racionalismo científico, o positivismo filosófico, o transformismo e o evolucionismo como um critério geral do pensamento", o "evolucionismo inglês, o materialismo de Haeckel, Moleschott, Buchner, o comtismo, a crítica de Strauss, Renan ou Taine, o socialismo integral de Proudhon, o socialismo literário de Hugo, de Quinet, de Michelet" (VERÍSSIMO, 1916, p. 43-52). Vale dizer que, para além da importância da categorização de sentido dada por Veríssimo a esse trânsito de ideias, ele próprio se faz testemunha dessa ambiência pensante, que chega até mesmo a impactar certa parte das suas próprias obras, sobretudo, no seu chamado "ciclo amazônico". O que unifica o modernismo é, em todas as suas manifestações regionais, o "preconceito da infalibilidade da ciência", assim como uma "exagerada opinião sobre a sua importância" (VERÍSSIMO, 1916), condições ideais para uma orientação e uma visão de mundo cientificistas (DETONI, 2019).

De todo modo, a natureza, ou a concretude do processo histórico, tudo aquilo que constitui o universo como tal, é percebida por Fausto Cardoso como matéria, amparado nas prescrições de Haeckel. Ela pode se desdobrar em física, orgânica ou social, fracionando-se em astros, organismos e sociedades. Toda essa disposição fenomênica possui uma base ancestral comum: a nebulosa primitiva. A partir dela, há uma plurievolução autônoma dos vários segmentos da matéria, havendo um princípio originário compartilhado. Diante dessa teoria, em que a matéria, ao invés de se mostrar una, performa-se a partir de formas diversas e cambiantes, cabe o exame da cadeia de sucessão e de coexistência dos corpos. Meios possíveis para se compreender a dinâmica fenomênica do mundo, qualquer que seja a sua categoria (física, orgânica ou social).

Para Cardoso, cada uma dessas categorias, independentemente da sua composição, possui um composto originário, isto é, as formas, constituídas pela fragmentação da matéria no tempo e no espaço, e as relações, elementos invisíveis que são importantes por aglutinarem as formas, dando-Ihes uma identidade. No universo das formas, nada é estável, fixo e permanente; enquanto que, nas relações, há um processo de enredamento durável, um "desenvolvimento contínuo", que é capaz de organizar o plano das formas materiais. Em resumo: o universo fenomênico é composto por corpos que se sucedem e que coexistem, sendo que ele tem apenas duas faces complementares, quais sejam, formas e relações. Sobre as formas a ciência nada pode dizer, pois a variabilidade da matéria natural e histórica é tamanha, que se torna impossível taxonomizá-la. A disposição própria das relações é o objeto da ciência. Elas aparecem, para Cardoso, como tudo aquilo que "resulta da existência e coexistência das formas", não tendo, 
"como estas, existência palpável". Sendo certo, contudo, "que o objeto da ciência será aquela face do universo que não muda", ou seja, a das relações, a maneira pela qual as formas se singularizam (CARDOSO, 1895a, p. 243). Elas oferecem, mesmo em estado de invisibilidade, um padrão ao mundo das formas, absolutamente errático, por meio de uma abstração empírica que abrange o desenvolvimento e o equilíbrio da matéria.

A partir dessa situação epistemológica, a ciência passa, então, a ter a seu lado a padronização das formas denominada de lei. Ela pode ser compreendida como uma relação necessária e universal que, através dos vetores tempo/espaço, apreende o mundo das formas por meio de regularidades. Em meio à multiplicidade de formas evolutivas, a lei capta a sua uniformidade crescente, ou seja, "o fato constante que une no mesmo laço os fenômenos mais diferentes e mais distantes, a imagem, em suma, unitária das formas, a síntese, o monograma da etiologia universal" (CARDOSO, 1895a, p. 243). A ciência é o aparato intelectivo humano capaz de colocar em evidência as leis, o mundo das relações que padroniza as formas. Destaca-se que Fausto Cardoso concebe lei e relação como sinônimos, sendo elas informadas empiricamente. $O$ enredamento relacional das formas ou o estabelecimento das leis é tangível. A lei é a mimeses da maneira pela qual as relações ordenam as formas. Quando uma lei é apreendida pela ciência, torna-se possível conceituá-la, derivando, daí, os princípios. Por isso, para Fausto Cardoso, "a ciência é a fotografia das leis" (CARDOSO, 1895a, p. 242).

O monismo haeckelista pretende compor e o percebemos através da sua recepção brasileira em Fausto Cardoso, uma teoria geral para o entendimento do funcionamento do universo como um todo. Três grandes princípios o explicam: 1) as formas que constituem a cadeia evolutiva universal derivam umas das outras, por força de um duplo movimento de convergência e de divergência; 2) as formas de que a evolução se reveste no tempo fixam-se no espaço em tipos sobreviventes e fixos; 3) a história de cada forma é uma recapitulação sumária da história da categoria a que pertence (CARDOSO, 1895a, p. 249).

Em tese, essas fórmulas informavam a realidade do mundo das relações, isto é, as leis fundamentais que sustentavam o funcionamento do universo. A ciência reclamava uma aparelhagem intelectiva capaz de traduzir os câmbios entre formas e relações como raciocínio a partir de imagens, o conhecimento visível da matéria e de conceitos, a elaboração abstrata das relações, quer dizer, das leis. Considerava-se que a dimensão lógica do pensamento se organizava como um reflexo do real, sendo a ciência esse espelho exteriorizado. As formas e as leis da natureza correspondiam, respectivamente, as imagens e os conceitos. Em resumo: o princípio era o conceito formulado; o conceito 
a disposição do saber estabilizada; e a lei o que era conhecido. Foi em razão disso que a ciência pôde, em tese, prognosticar com exatidão, na medida em que havia uma equação epistemológica que traduzia mimeticamente o universo fenomênico seja qual for a sua categoria (física, orgânica ou social). Portanto, pode-se argumentar, no limite, que

as ciências são corpos de doutrina, conjuntos de princípios, teorias capazes de verificações e previsões certas e indubitáveis: é o espelho em que se reflete o mundo das relações no tempo e no espaço palingenética e ontogeneticamente, e o são tais, porque lei, conceito e princípio exprimem o mesmo fato em condições diversas de existência, em roupagens diferentes (CARDOSO, 1895a, p. 251).

\section{Sobre as impossibilidades da história como ciência}

Sílvio Romero, contemporâneo de Escola de Recife de Fausto Cardoso, esclarece em sua influente História da literatura brasileira, de 1888, que naquilo que tange a "nova classificação das ciências", as quais se orientam através da "ordem crescente da complexidade dos fenômenos e na decrescente de sua generalidade", parece possível observá-las sob uma perspectiva que estabelece o "grau atingindo de sua certeza". Nessa ordem de propósitos, encontram-se as ciências propriamente ditas, as quase ciências e as falsas ciências. No primeiro grupo: a matemática, a astronomia e a física. No segundo: a psicologia, a história e a economia política. No terceiro: a metafísica e a teologia. Nas modalidades analíticas que inscrevem homens e mulheres em sociedade sob o vetor histórico, o mote classificatório é circunscrito pelo segundo grupo mencionado. Isso ocorre em virtude desses domínios não terem "atingido o grau de certeza que constitui o brilho próprio das completas ciências". A história, "por maiores que tenham sido os esforços de Buckle e seus continuadores", que buscam estabelecer leis históricas fundamentais, certamente ainda está "resignada a não deixar, por hora, o círculo de suas companheiras, quer dizer, as quase ciências" (ROMERO, 1902, p. 23). Ao que tudo indica esse parecer de Sílvio Romero era compartilhado por Fausto Cardoso em sua caracterização epistemológica sobre a história presente em "A ciência da história".

Se a propedêutica dos artigos de Fausto Cardoso compreendia a apreciação da dinâmica interna da prática científica, o seu desenvolvimento relacionava-se com a sua aplicabilidade em se tratando do conhecimento histórico. Era a história uma ciência? 
Para a perfeita averiguação dessa questão epistêmica, se fazia necessário o estabelecimento de algumas premissas consideradas importantes: a história era um corpo doutrinário, um conjunto de princípios através dos quais se podia verificar e prever de maneira certa e indubitável os planos, ou a "marcha", no tempo e no espaço das forças sociais? A resposta, já no início do segundo artigo da referida série de artigos, era negativa. A história não tinha à disposição princípios tampouco normas. Não formava um sistema doutrinário apto a efetivar verificações teóricas informadas empiricamente e previsões. Essa conclusão de Fausto Cardoso surpreendia pelo seu grau de sofisticação, em se tratando de teoria da história. Em um universo letrado, no qual o peso do cientificismo era visível nos mais diversificados modos de investigação da realidade social do mundo, a interpretação de Fausto Cardoso, informada pelo haeckelismo, aparecia como um contradiscurso ao progresso científico-disciplinar da história. Isso em um momento que, no contexto brasileiro, como quer Temístocles Cezar, "os conceitos de história e de historiador adquirem um contorno mais científico" (CEZAR, 2011, p. 99).

A história é, segundo o estudioso sergipano, praticada por três categorias de intelectuais: 1) os empiristas: os historiadores stricto sensu. Sujeitos que escrevem crônicas, biografias, narrativas acontecimentais e realizam descrições sobre as civilizações; 2) os idealistas: aqueles que interpretam a história como um todo dotado de coesão, a partir de uma cadeia de fatos que se sucedem presididos por uma vontade providencial, ou por uma razão inteligente; 3 ) os naturalistas: intelectuais que compreendem a humanidade como um elemento da natureza enredado por leis. De acordo com Fausto Cardoso, no primeiro grupo estão, como visto, os historiadores propriamente ditos; no segundo, os filósofos da história; no terceiro, os sociólogos. De forma tal que essas categorizações de sentido acerca da prática daqueles que se ocupam com a história é bastante esclarecedora: artistas, metafísicos e biólogos da história.

A percepção de Fausto Cardoso sobre a prática historiográfica, abrangendo cronistas, biógrafos e narradores em geral, é que tal prática se modula através do registro empírico dos fatos, performando-se através da construção de quadros descritivos, com "maior ou menor beleza" ou com "mais ou menos veracidade". É bem verdade, argumenta o articulista, que há uma revolução historiográfica de Heródoto à Mommsem. No entanto, essa transformação apenas altera os métodos narrativos e descritivos, e não o seu objeto, que invariavelmente continua o mesmo, isto é, a descrição do lado visível e tangível da história: homens, sociedades, acontecimentos e civilizações. Dito de outra forma: a história não transcendia as formas em direção às relações ou leis. 
Isso implicava na sua não cientificidade, dado que esse saber destacava a singularidade da matéria, sendo que ela não era passível, como abordado, de determinações regulares no âmbito das formas. Devia-se ir ao encontro das leis, o universo das relações, responsáveis por dar identidade e sentido para as formas. Dessa maneira, guardadas as especificidades implicadas nos modos de apropriação das correntes científicas em circulação no Brasil,

um leitor mais atento irá perceber que há uma única concepção de ciência, orientando todo percurso através do tempo e do espaço. É aquela baseada no paradigma das ciências naturais, vigente no mundo europeu do século XVI ao XIX, aproximadamente. Uma concepção de ciência que entende que o mundo, físico e social, é regulado por leis (GOMES, 2009, p. 42).

Todavia, mesmo nessas circunstâncias, vê-se que a produção historiográfica disponível naquele contexto passa, na visão de Cardoso, por um avanço considerável. Colocar em evidência essa percepção torna o seu texto um indício da produção histórica brasileira finissecular. $O$ ser dos fatos deve ser descrito, nessa conjuntura, para além da sua aparência superficial. À luz de diversos processos da pesquisa histórica, desde procedimentos técnicos até os recursos das chamadas ciências auxiliares da história, períodos inteiros inscritos no plano da evolução aparecem mais visíveis e definidos. Notáveis quadros imagéticos do passado são construídos. Ademais, o campo de visão do historiador é alargado e fenômenos, que o Romantismo supostamente interpreta de modo incipiente, são recolocados em evidência: as línguas, as legislações, as religiões, as literaturas, as artes, as invenções, as indústrias, os costumes, as antiguidades de todo gênero, a criminalidade e a economia. Tudo "isto foi estudado e analisado em seus menores detalhes. $\mathrm{E}$ a arte de historiar revestiu um caráter mais elevado: os acontecimentos foram concatenados, os fatos ligados" (CARDOSO, 1895b, p. 76).

Mas esse movimento geral da historiografia não oferece, pois, uma abertura possível para a sua elevação ao grau de ciência? A solução para esse questionamento passa por um intrincado problema de epistemologia. Para Fausto Cardoso, a ciência não consiste somente na ligação entre os fatos, pois, sendo assim até mesmo o literato pode muito bem urdir uma intriga qualquer e nominar esse procedimento de ciência. Não é por acaso que o autor denomina os historiadores como artistas. Assim, o produto científico deve, necessariamente, ser teórico-explicativo. No limite, a história, da maneira como até aquele momento é praticada, registrando, examinando, descrevendo, ligando e demonstrando os fatos, mostra-se como um produto intelectivo que pode apenas constituir a parte descritiva de uma futura ciência. A explicação, em qualquer ciência, 
consiste na compreensão filogenética (classificação) e ontogenética (o processo em si) de um fenômeno, apreendendo a sua evolução geral e particular por meio de um corpo doutrinário e movimentando duas dimensões: empírica e lógica, sendo a passagem das formas para as relações ou leis. As pesquisas em história não ultrapassam, na percepção de Cardoso, o mundo visível das formas, seja em razão da soma dos fatos registrados não parecer suficiente para formar conjuntos lógicos de princípios, seja por conta do historiador ter se esquivado de penetrar o mundo invisível das relações. De todo modo, o conhecimento histórico é imagético e não conceitual. Por isso, ele não se eleva ao patamar das "grandes induções" que formam as doutrinas científicas. O saber histórico

não passa de um registro de observações mais ou menos verdadeiras, de fatos mais ou menos comprovados - um árido montão de pedras à espera do liame que tem de transformá-la em belo edifício. Eis aí porque dissemos que, sob o ponto de vista dos historiadores propriamente ditos, a história é, quando muito, a parte descritiva de uma futura ciência; é a arte de narrar os sucessos (CARDOSO, 1895b, p. 76).

Em seu estudo sobre o conjunto de artigos "A ciência da história", Mauro Franco Neto argumenta que não é preciso que o nosso autor defina o regramento que atravessa a ciência, pois, em última instância, "é o próprio discurso histórico, prenhe de incertezas, incoerências e incapaz de prever, que possibilita a Cardoso avistar os limites de uma ciência e os paradoxos que ela deveria ora ou outra enfrentar" (NETO, 2015, p. 169).

O que estamos expondo até aqui é que o evolucionismo de marca haeckelista de Fausto Cardoso apresentava-se como um indício da epistemologia das ciências visível no final do século XIX. Nesse contexto, o conhecimento acerca da natureza e dos sujeitos históricos imbricava-se, para parte daqueles intelectuais, através de uma chave de leitura na qual havia o entendimento das relações entre os mundos inorgânico, orgânico e superorgânico (cultural), sendo que era exigido o deslindamento das leis naturais que comandavam os fenômenos observados, tarefa das mais distintas matrizes científicas, sobretudo, de cariz biológico. Era esse processo epistêmico que a história não alcançava, posto que se o seu objeto era o particular, o singular, o único, o distintivo; longe, então, dos padrões científicos exigidos. A história se orientava, até aquele dado momento, pela produção de imagens e não de conceituações. Ademais, ela não congregava, como era amplamente demandado, a análise do fenômeno cultural (superorgânico) justaposto ao mundo orgânico, ou seja, a história tendia a não avançar no domínio das relações biossociais evolucionistas, mantendo-se na visibilidade inconstante das formas. 


\section{As teorias da história nos horizontes do cientificismo naturalista}

Certamente, um dos elementos mais destacados inscritos nesse contexto epistêmico-historiográfico estava ligado à questão da posição do sujeito histórico em sociedade. Ou melhor: "sobre as razões que movem a ação dos indivíduos e a 'evolução' dos grupos e das sociedades humanas" (GOMES, 2009, p. 34). Assim, a geração de 1870 se via desafiada a compreender se a explicação da ação humana, o "motor da história", era movimentada pelo livre-arbítrio ou, de outra forma, através das modalidades deterministas disponíveis. Além dessa provocação evolucionista, a história deve se ocupar com a ideia kantiana de que a natureza é um mecanismo que se comporta "em relação a si mesmo reciprocamente como causa e como efeito", renunciando a qualquer outro fim (KANT, 2005, p. 213). Esses dois vetores apareciam como desafios ao caráter reflexivo da história no período, seja qual for o esquema explicativo mobilizado por ela.

Fausto Cardoso avalia, então, as formulações teóricas sobre a história que considera em circulação no final do século XIX. São elas: 1) o providencialismo, que explica a história através da intervenção de uma força divina, suprema e absoluta; 2) o racionalismo, que procura na razão humana a causa de todos os acontecimentos que movimentam o domínio social; 3) o naturalismo, que concebe a humanidade como um elemento da natureza atravessado por leis. Segundo o estudioso, o providencialismo e o racionalismo são inatuais ante o naturalismo, dimensão teorética da história em destaque naquele final de século. Assim, vê-se que, desde a modernidade, a dimensão providencial da história apresenta-se como uma fórmula explicativa em gradativo descompasso com os princípios que regem a realidade das transformações históricas (KOSELLECK, 2006). Cardoso confirma o ensejo: "A ciência só se levanta sobre as ruínas da fé" (CARDOSO, 1895b, p. 78). Já o racionalismo, que se materializa em filosofias da história, também não acessa uma teoria científica da história, posto que essa postura de pensamento não é fruto de observações e de princípios lógicos abrangentes e seguros, além de apenas ligar narrativamente os eventos históricos, não os explicando. O racionalismo é, para o intelectual sergipano, obra de abstrações idealistas que se formam nas categorias do espírito para serem sobrepostas à realidade. A falha epistêmica do racionalismo ou teoria libero-racional localiza-se, para além do seu dualismo, na presunção de tornar o livre-arbítrio o seu princípio fundamental. Além de esse princípio não movimentar explicações científicas junto à história, dado que, se aceito, as ações humanas deixam de ser perpassadas por qualquer forma de determinação, ele eleva o homem a centro do universo. 
As teorias explicativas da história, providencial e racional, levam ao que Fausto Cardoso chama de dualismo, que tem vigorado desde os gregos no que tange à compreensão da ordem social. Esse desdobramento das teorias providencial e racional, pondera Cardoso, considera a natureza e a história como instâncias separadas, duais, em que não prevalece qualquer forma de determinação, pois vigora a ideia da responsabilidade, derivada do livre-arbítrio, humana individual, inteira e completa. $\mathrm{O}$ nosso autor, nesse sentido, constata que esses padrões explicativos partem de fórmulas abstratas e absolutas, formando ideologias e correntes ditas científicas que se realizam, conforme as suas palavras, verdadeiramente de "cima para baixo".

Desde ao menos 1878, quando Capistrano de Abreu escreveu o "Necrológio de Francisco Adolfo de Varnhagen, Visconde de Porto Seguro", estava lançada a ideia na qual o plano teórico da historiografia, que Capistrano dava o nome de "estudos históricos", devia se orientar através do cientificismo em circulação no Brasil. Capistrano de Abreu, ao falar das limitações da prática historiográfica modelar de Varnhagen, assinala o seguinte: "pena que ignorasse ou desdenhasse o corpo de doutrinas criadoras que nos últimos anos se constituíram em ciência sob o nome de sociologia. Sem esse facho luminoso, ele não podia ver o modo por que se elabora a vida social" (ABREU, 2015, p. 31). Já José Oiticica aponta, em 1910, que "os nossos melhores historiógrafos", via de regra, "baralharam sempre os acontecimentos, nunca os separaram uns dos outros, nem lhes deram, com precisão, a influência por eles exercida na evolução da sociedade brasileira" (OITICICA, 1910, p. 110), em razão de não possuírem um plano teórico com feições científicas, o que impossibilita a classificação e a teorização de tais fatos. Enquanto isso, Sílvio Romero não concebe nenhuma originalidade na atuante proposta de história filosófica de Karl von Martius, considerando-a desatualizada em termos de ciências, como no caso da etnografia. Na esteira da crítica de Romero reside o fato de o naturalista bávaro não movimentar as ciências correntes como aporte teórico para a historiografia, apegando-se a uma dimensão filosófica, em tese, facilmente refutada em termos científicos (ROMERO, 1902). Portanto, é a partir dessa conjuntura historiográfica que devemos compreender as prescrições presentes em "A ciência da história". No limite, está em jogo a legitimidade da história ante as pressões do cientificismo. Porém, o que salta aos olhos nas reflexões de Fausto Cardoso é o seu prognóstico diante dessa demanda.

Diante do que foi exposto e acompanhado as performances do espectro naturalista, encontramos os seguintes tipos de agentes intelectuais arrolados por nosso bacharel em direito: os psicólogos, os físicos e os biólogos da sociedade, que respectivamente são os psicólogos dos povos, os historiadores filósofos e os sociólogos. 
A teoria psicológica unifica, em seu entender, racionalismo e naturalismo. Porém, ela transcende $o$ individualismo racionalizador. Ela advoga que as nações possuem, como os indivíduos, uma psicologia que pode ser comparada. As suas conclusões modulamse como princípios diretores e universais diante da explicação histórica. A teoria da evolução social não é senão a aplicação particular da teoria da formação do caráter nacional, o qual pode ser obtido pela generalização psicológica. Percebe-se, assim, que a psicologia dos povos, uma teoria coletivista da história, apresenta-se para Cardoso como uma generalização do racionalismo realizada através da analogia biológica. Se, antes, o racionalismo era atravessado pelo idealismo, agora ele era abordado pelo prisma das ciências naturais. A convicção antiga de que as ações de homens e de mulheres aparecem individualmente como as únicas realidades históricas tangíveis, a verdadeira força do sistema social, transforma-se à luz das ciências naturais, que através dos procedimentos de analogia faz ver a unidade orgânico-social informar um todo coletivo específico. Mas amparado pelas "Variações anti-sociológicas" de Tobias Barreto, Fausto Cardoso conclui que a psicologia dos povos, como teoria da história, não se configura como produto intelectual científico. Nela não se vê, apesar dos inegáveis avanços epistemológicos, uma fórmula capital, um conjunto de princípios, normas morais e intelectuais que Ihe inspirem na prática e nas verificações e previsões teóricoempíricas.

Entre os historiadores filósofos, armados com o determinismo mesológico, de largo sucesso na segunda metade do século XIX, destaca-se, para Cardoso, Henry Thomas Buckle, autor da History of Civilization in England, de 1857. A proposição teórica de Buckle é simples: conforme as sociedades submetem a natureza, maior o seu progresso. Essa ideia deve ser concebida como universal, sendo que, a partir dela, se podem contextualizar todos os povos. Esse princípio sustenta, em tese, a cientificidade da história. Mas mesmo que Fausto Cardoso reconheça todo o esforço teórico de Buckle, considerando que ele é quem mais chega próximo de estruturar a história cientificamente, o seu determinismo mesológico encobre uma orientação psicológica coletiva importante, isto é, a hereditariedade psíquica. Não basta o historiador, nessa chave de leitura, contextualizar espacialmente homens e mulheres, pois o determinismo psíquico, hereditário, alega que, independente do contexto mesológico em que estão inseridos, esses agentes sociais são guiados por uma ancestralidade mental (positiva ou negativa). Essa conclusão parece-nos muito próxima do princípio haeckelista, o qual admite que cada sujeito carrega consigo a história da evolução da sua classe. Em suma, as histórias filosóficas, cujo maior artífice é Buckle, não podem estabelecer padrões científicos universais para os domínios da história. De todo modo, no momento em que Cardoso interpreta as contribuições do estudioso britânico, durante a década 
de 1890, "a obra já havia sido lida, em sua versão original ou na tradução francesa, por Tobias Barreto, Capistrano de Abreu e Araripe Jr, por exemplo". Incluímos Sílvio Romero. Luciana Murari assevera, então, que, no contexto historiográfico em que ele comenta as teorias de Buckle, é expressivo que o seu pensamento já não mais resiste às críticas locais (MURARI, 2002, p. 103).

Para Cardoso, quando, à luz da biologia, a sociedade se faz compreendida como organismo vivo, essas duas noções fundem-se, dando origem a um novo grupo intelectual, qual seja, os sociólogos modernos. Mas a sociologia, como as demais teorias explicativas da história, não se conforma como uma ciência per si. É um campo em formação. Mesmo assim, ela se mostra como o melhor registro interpretativo que a história dispõe, sendo necessário, ao mesmo tempo, transformar as leis que o naturalismo biológico movimenta em um conjunto de princípios aplicados à sociedade em perspectiva histórica. A sociologia apresenta-se não como ciência explicativa da história, mas como uma dedução biológica informada historicamente. Essa é a grande forma de interpretação histórica do momento.

A ideia sociológica corrente de que a humanidade pode ser percebida como um elemento natural absoluto, que, em seu desenvolvimento obedece, como na natureza física e orgânica, a marcha regular dos organismos sociais, princípio do naturalismo, que alimenta discussões com desdobramentos investigativos no Oitocentos, é uma sentença epistêmica, segundo Fausto Cardoso, que oscila de maneira ainda indefinida e sem uma formulação acabada, não constituindo um corpo doutrinário em se tratando de ciências sociais. É uma verdade, prossegue o autor, que ainda procura se definir epistemicamente para se tornar uma doutrina operatória entre os analistas do social.

Além disso, certas vertentes sociológicas, que, em tese, deveriam resolver esses problemas junto à explicação histórica, elaboram-se a partir de um naturalismo considerado equivocado: que encara a vida social como uma projeção orgânica, porém, de natureza dualista. A sociedade, como corpo social ou como organismo social, não pode, argumenta o estudioso, ser a soma de parcelas iguais à unidade somática, mas uma soma de elementos análogos. Isso em razão da falta de igualdade das parcelas tornar impossível essa soma orgânica, que é a representação da sociedade implicada no conceito sociológico falsamente naturalista. De qualquer maneira, congregar a ordem orgânica com a social é uma operação em vias de se tornar científica. São domínios, sublinha Cardoso, diferentes que podem, sim, se justapor. Um é constituído pela natureza viva em suas diversas manifestações; enquanto que o outro é formado pela cultura e pela civilização, abrangendo todas as modalidades 
sociais e políticas. Os câmbios entre natureza e sociedade apresentam-se como um fato inquestionável objetivamente. É, então, um destino manifesto monístico, mas, no domínio lógico, no mundo dos princípios, mostra-se como uma aspiração em processo de estabilização. A sociologia não se configura como uma teoria propriamente científica da história, mas como um domínio inferencial da biologia que explica o processo histórico.

Assim, a questão se a história era ciência, quer do ponto de vista descritivo, quer sob o reflexivo, ou ainda através da ótica da filosofia da história, da história filosófica, da psicologia e da sociologia, estava sem solução. Nas mãos dos narrativistas, assegura Cardoso, a história modulava-se como um "monstruoso registro" puramente empírico; entre os filósofos da história, o idealismo se fazia valer; com os historiadores filósofos, era apenas uma dedução mesológica; dentre os psicólogos do povo, mesmo havendo a percepção da suspensão do dualismo e do individualismo, não se percebia um registro doutrinário, mas apenas um fraco sistema analítico; por fim, ao ser explicada pelos sociólogos, era uma pura dedução biológica, ou seja, nem uma das teorias da história disponíveis, aos olhos do intelectual sergipano, a elevavam ao patamar de ciência. "Não é uma ciência, é um montão de fatos, coberto por uma rede de conjecturas" (CARDOSO, 1895e, p. 154).

\section{Monismo, adaptabilidade e hereditariedade como fundamentos sociais}

A recepção dos novos ideários sociais a partir da década de 1870, na maioria dos casos atravessados pelo cientificismo, tendo como principal, mas não única, referência o positivismo de Comte e de Spencer, tendeu a conduzir o país para uma perspectiva ideológica favorável ao trabalho livre e para realização de um novo regime político. A partir "das gerações de 1870" uma nova plêiade de intelectuais (também políticos e publicistas) apropriou-se do prestígio daquelas ciências europeias, para instaurar uma espécie de aggiornamento junto ao pensamento local. É nesse quadro de inflexões e de rupturas conflitantes que novos grupos político-intelectuais deixam de ser marginais (ALONSO, 2002), desatualizando o legado romântico, o seu ecletismo espiritualista de matriz francesa, bem como os compromissos políticos com o Estado monárquico. Através dessa atmosfera reformista, a intelectualidade brasileira passou a tentar compassar tempo social e tempo político, em um movimento de consciência histórica que buscava estabelecer uma sintonia entre aquilo que se era com aquilo que se pretendia ser. Conforme Fernando Nicolazzi, "escrever sobre a nação, elaborar a sua história, era também uma forma complexa de ordenamento do tempo" (NICOLAZZI, 2015, p. 48). 
A promoção do naturalismo, por exemplo, estava intimamente ligada a um ideal de ciência com autoridade suficiente para ilustrar o país. Para Roberto Schwarz, essa linguagem, "tão prestigiosamente moderna quanto estranha à vida corrente, anunciava rupturas radicais; prometia substituir o mecanismo atrasado da patronagem oligárquica por espécies novas de autoridade, fundadas na ciência e no mérito intelectual" (SCHWARZ, 1990, p. 143). É necessário, então, salientar que a apropriação dessa modalidade de cientificismo prometia a projeção de uma sociedade em estado de modernização, marcada, assim, por um claro apelo racional e neocivilizador.

A partir dessa disposição sócio-epistêmica vemos, então, o monismo circulando como um registro intelectual, que suspendia o véu das aparências sociais, sobretudo, em seu âmbito institucional. É um princípio que se torna cada vez mais comprovadamente científico, para Fausto Cardoso. Em um primeiro momento, esse esquema de pensamento volta-se contra a ordem imperial saquarema (MATTOS, 1987), porém, não muito distante dali essa mesma plataforma intelectual contesta a própria legitimidade do desenvolvimento político da jovem República Federativa (como em Fausto Cardoso). O significado da persistência desse dualismo político pode ver visto nesta passagem:

A política continua a nutrir-se de princípios, de métodos e alvos abstratos e inacessíveis aos processos de observação do espírito humano. A ter por base a intuição dualista do universo; por objeto o estado considerado como uma livre criação do homem, em coexistência com outras entidades abstratas que o racionalismo criou, - vive, no remanso das indagações metafísicas, fora da influência renovadora do espírito naturalístico do século, que tudo transformou, - artes, literaturas, filosofia, religião, todas as disciplinas, todas as criações humanas, em suma (CARDOSO, 1895e, p. 143).

Assim, antes de qualquer coisa, a sociedade imaginada por Fausto Cardoso deve ser concebida fora das premissas filosóficas do dualismo, ou seja, de um movimento que separa sujeito e objeto, essência e aparência, ideia e matéria, instituição e sociedade. Em termos políticos busca-se, monisticamente, uma concepção unitária de Estado e de sociedade. Distancia-se, assim, de uma posição na qual o Estado sujeita a sociedade aos seus desígnios, dando lhe uma razão a priori e um sentido predeterminado.

O desafio de Cardoso é demonstrar que o Estado, que tem um desenvolvimento próprio, não pode orquestrar a sociedade através de preceitos metafísicos. O esquema dualista Estado/sociedade assemelha-se, então, à separação entre corpo e espírito. 0 problema consiste no fato de que, para a superação dessa abordagem, necessita-se da 
instrumentalização autoritária, mesmo que provisória, do plano político institucional. Nem mesmo Tobias Barreto, sabidamente monista, escapou da sua crítica. O grande arauto da Escola de Recife também caiu, em tese, nessa armadilha da formação do Estado. Ele ofereceu, pois, um arranjo finalístico à sociedade. Na percepção de Cardoso, Tobias sanciona, ao tomar como verdadeiras as proposições de Friedrich Fröebel, o dualismo que tanto combate e que se mostra fortemente presente entre as teorias político-sociais disponíveis.

O contexto finissecular apresentou uma série de teorias sociais divergentes que informavam o saber histórico. Em muitos casos havia, inclusive, confusão conceitual sobre os significados de povo, de nação, de nacionalidade e de Estado agenciados por elas. Mas talvez daí resultou a originalidade do cientificismo brasileiro. Havia, ademais, variedade explicativa: geográfica, filológica, etnográfica e moral. Também era comum, nessas abordagens circulantes, certo apelo teleológico, cabendo ao futuro do século XIX assistir o nascimento verdadeiro das nacionalidades ou das nações naturais.

Mas a partir do exposto há, em todo caso, uma conclusão que pode ser salientada, argumenta Cardoso. Como foi visto, a história das ciências obedece a uma configuração própria. A disciplina história não pode ser uma exceção à lei que orienta esse desenvolvimento epistemológico. Ela, segundo a sua teoria do saber, aparece como uma dedução da biologia antes de ser uma ciência. A história é explicada através da sociologia como inferência biológica. Desse modo, para fechar o plano teórico de Cardoso se faz necessário este entendimento: a partir das descobertas de Jean-Baptiste Lamarck e Charles Darwin é possível transpor para o plano social o princípio da "herança".

Assim, amparando-se no campo da biologia a partir do domínio reflexivo que se pauta por essa disposição explicativa, a teoria da história, que já se guiou, em seu entender, através do sobrenatural, o providencialismo, e do racional, o racionalismo, começa a orientar-se, por meio da sociologia, através de uma base organicista/naturalista.

O grande desafio da biologia repousava na solução do problema da transformação, quer dizer, da mudança e do encadeamento das formas com verificação científica, sejam elas vivas ou extintas. Na medida em que se faz capaz de apontar essas lógicas, ela mesma se assume como o nexo que congrega todo o saber humano, como a força intelectual unificadora do mundo e como o próprio conhecimento como "natureza em evolução" (DÓRIA, 2007). Fausto Cardoso habilitou os seus textos, projetando um lugar para a história, a partir desse horizonte de significação discursiva. 
Essa discussão evolucionista tornava disponível o tema capital do "núcleo duro" da doutrina darwinista: a seleção natural. Havia, a partir do darwinismo, que podia ser dissolvido principalmente no haeckelismo e no spencerismo, posições interpretativas biológicas stricto sensu e culturalistas, as quais compreendiam e aplicavam esse princípio socialmente, ambas com desdobramentos junto ao âmbito da história. De um lado, vemos a circulação de temas como o biotipo brasileiro, a sua capacidade e alcance mental, as suas patologias, os seus cruzamentos interraciais, dado que, para essa vertente, o plano das coletividades era assimilado como conjuntos de indivíduos que expressavam qualidades biológicas. Em certo sentido, o conhecimento sobre a biologia individual podia generalizar-se, visando ao entendimento social. Essas reflexões eram mais comuns entre os médicos formados por nossas poucas faculdades, representados socialmente como "missionários do progresso" (HERSCHMANN, 1996), bem como por toda uma gama de antropólogos. Já na perspectiva culturalista, mais presente entre aqueles formados nas faculdades de ciências jurídicas, como Fausto Cardoso, a diagnose histórica brasileira passava, como anunciado, pela admissão da sociedade como organismo coletivo e vivo regido pelas leis do programa naturalista, o que impacta substancialmente a compreensão acerca das instituições, da cultura e do destino histórico da nação, sendo os sujeitos históricos subordinados a essa dinâmica (DÓRIA, 2007), em que não raro perguntar-se pelo arbítrio (GOMES, 2009) ou pela degeneração (SCHWARCZ, 2018).

A ênfase na adaptação era uma dimensão comum, dado que ela tornava viável a formação do povo através da interação racial com a natureza. A adaptabilidade era o respaldo teórico de certo determinismo mesológico de Fausto Cardoso. A outra parte do núcleo duro darwinista, a hereditariedade, era assinalada a partir da ideia a qual a evolução biossocial era devedora de uma herança de caracteres adquiridos e legados, fossem eles positivos ou atávicos. Em relação a Cardoso, havia uma dimensão psíquicodeterminista herdada. Assim, pode-se argumentar, acompanhando o seu contemporâneo Sílvio Romero, que "a hereditariedade é uma força sem a qual não se concebe a própria vida" (ROMERO, 1906, p. 186). Através do darwinismo social, o nosso autor elaborou o processo histórico, configurando-o por meio de uma dinâmica em que os agentes se acomodavam no meio e se desenvolviam por meio de continuidades psicológicas.

\section{Consideraçōes finais}

"A ciência da história", série de prescrições formulada por Fausto Cardoso, em 1895 , evidencia um importante circuito de saber que amparava os debates intelectuais finisseculares, qual seja, aquele que se manifestava através da teoria da evolução, do 
darwinismo social e de um conhecimento modulado através das chamadas ciências naturais. Estamos, de fato, no terreno do cientificismo à brasileira, sendo os textos do bacharel em direito sergipano importantes para a complexificação dessa ambiência epistêmico-historiográfica a partir de uma voz relativamente emudecida.

Mas a originalidade dos apontamentos desse estudioso passava pela problematização de um dos elementos fundantes e estruturantes da "moderna historiografia brasileira": a sua cientificidade. Esse questionamento não era de menor importância, na medida em que ele estava inserido em uma plataforma disciplinar que, majoritariamente, confiava na objetividade dos aportes científicos em circulação.

No momento da publicação dos textos em questão, Cardoso era professor de filosofia do direito na Faculdade de Direito do Rio de Janeiro, o que nos faz imaginar que ele estava em uma franca conversação epistêmica com esse campo, que desejava o posto de ciência social a partir da "respectiva reconstrução histórica mediada por leis do desenvolvimento" (NETO, 2015, p. 167). Fausto Cardoso não deixava de prescrever uma definição para a ciência, que, segundo ele, teria a capacidade entrever verificações e previsões absolutas. Contudo, esse preâmbulo foi construído com a intenção de questionar os alcances desse tipo de saber junto à ordem natural do mundo atravessada pela configuração histórica. Para o nosso autor, nesse âmbito, a nomologia se desestabilizava ante a inconstância dos seus objetos. Essa afirmação trazia consequências imediatas tanto para o direito quanto para a história, dado que impedia o estabelecimento da verdade histórica como um produto derivado da adequação relacional das formas.

De qualquer maneira, ele chega a esse raciocínio epistêmico a partir da consciência acerca da incapacidade do discurso histórico de reunir e de uniformizar as ruínas do passado, em sua desventura de emprestar-Ihes um sentido, dado que perpassado pelo signo da falta, pelo horizonte da incerteza e pela incapacidade da mimese. É esse movimento que retira, então, o seu caráter científico. Mas é a partir da própria delimitação dos alcances e dos limites do saber histórico que Cardoso vai reestruturando na economia mesma dos seus textos os sentidos da sua percepção acerca da ciência, desdobrando-se em uma intricada explicação do mundo humano sob as bases do darwinismo social. 


\section{REFERÊNCIAS}

ABREU, João Capistrano. Necrológio de Francisco Adolfo de Varnhagen, Visconde de Porto Seguro. In: NICOLAZZI, Fernando (org.). História e historiadores do Brasil: do fim do império ao alvorecer da República. Porto Alegre: EDIPUCRS, 2015. p. 13-32.

ALONSO, Ângela. Ideias em movimento: a geração de 1870 na crise do Brasil-Império. São Paulo: Paz e Terra, 2002.

BRESCIANI, Maria Stella Martins. O charme da ciência e a sedução da objetividade. Oliveira Viana entre intérpretes do Brasil. São Paulo: UNESP, 2005.

CANDIDO, Antonio. A sociologia no Brasil. Tempo social, São Paulo, v. 18, n. 1, p. 271-301, 2006. Disponível em: http://www.revistas.usp.br/ts/article/view/12503. Acesso em: 25 jan. 2020.

CARDOSO, Fausto. A ciência da história. Revista Brasileira, Rio de Janeiro, ano I, tomo II, fascículo V, p. 237-251, 1895a.

CARDOSO, Fausto. A ciência da história. Revista Brasileira, Rio de Janeiro, ano I, tomo II, fascículo VIII, p. 74-89, 1895b.

CARDOSO, Fausto. A ciência da história. Revista Brasileira, Rio de Janeiro, ano I, tomo III, fascículo XIII, p. 45-59, 1895c.

CARDOSO, Fausto. A ciência da história. Revista Brasileira, Rio de Janeiro, ano I, tomo III, fascículo XVII, p. 295-309, 1895d.

CARDOSO, Fausto. A ciência da história. Revista Brasileira, ano I, t. IV, fascículo XXI, p. $140-154,1895$ e.

CEZAR, Temístocles. Lições sobre a escrita da história: as primeiras escolhas do IHGB. In: PEREIRA DAS NEVES, Lucia Maria Bastos et al. (org.). Estudos de historiografia brasileira. Rio de Janeiro: FGV, 2011. p. 93-124.

CHARTIER, Roger. A história cultural entre práticas e representações. Tradução de Maria Manuela Galhardo. Lisboa: Difel, 1990. 
DETONI, Vicente da Silveira. A moderna historia magistra vitae de José Oiticica: regimes historiográficos e ordem do tempo no Brasil (c. 1870 - 1940). 2019. Dissertação (Mestrado em História) - Programa de Pós-graduação em História, Universidade Federal do Rio Grande do Sul, Porto Alegre, 2019. Disponível em: https://lume.ufrgs.br/ handle/10183/206273. Acesso em: 29 mar. 2020.

DÓRIA, Carlos Alberto. Cadências e decadências do Brasil (o futuro da nação à sombra de Darwin, Haeckel e Spencer). 2007. Tese (Doutorado em sociologia) - Curso de Pós-graduação em Sociologia, Universidade de Campinas, Campinas, 2007. Disponível em: http://www.repositorio.unicamp.br/handle/REPOSIP/281054. Acesso em: 11 fev. 2020.

GOMES, Angela de Castro. A reflexão teórico-metodológica dos historiadores brasileiros: contribuições para pensar a nossa História. In: GUAZELLI, Carlos A. Barcellos et al. (org.). Questões de teoria e metodologia da história. Porto Alegre: Editora da UFRGS, 2000. p. 19-26.

GOMES, Angela de Castro. A república, a história e o IHGB. Belo Horizonte: Argumentum, 2009.

GUIMARÃES, Manoel Luiz Salgado. Historiografia e cultura histórica: notas para um debate. Ágora, Vitória, vol. 11, p. 31-47, 2005.

HERSCHMANN, Micael. Entre a insalubridade e a ignorância: a construção do campo médico e do ideário moderno no Brasil. In: KROPF, Simone; HERSCHMANN, Micael; NUNES, Clarice (org.). Missionários do progresso. Rio de Janeiro: Diadorim, 1996. p. 11-67.

KANT, Immanuel. Crítica da faculdade do juízo. Tradução de Valério Rohden e Antônio Marques. São Paulo: Forense Universitária, 2005.

KOSELLECK, Reinhart. Historia Magistra Vitae. Sobre a dissolução do topos na história moderna em movimento". In: KOSELLECK, Reinhart. Futuro passado. Contribuição à semântica dos tempos históricos. Tradução de Wilma Patrícia Maas e Carlos Almeida Pereira. Rio de Janeiro: Contraponto, 2006. p. 41-60.

KUNHN, Thomas. A estrutura das revoluções científicas. Tradução: Beatriz Vianna Boeira e Nelson Boeira. São Paulo: Perspectiva, 1975. 
MATTOS, Ilmar Rohloff de. O tempo Saquarema. São Paulo: HUCITEC; Brasília: INL, 1987.

MURARI, Luciana. Tudo mais é paisagem. Representações da natureza na cultura brasileira. 2002. Tese (Doutorado em História). Programa de Pós-graduação em História Social, Universidade São Paulo, São Paulo, 2002. Disponível em: https://cutt.ly/BxVx7Cf. Acesso em: 22 fev. 2020.

NETO, Mauro Franco. Ciência, evolução e experiência do tempo no fin de siècle: estudos e revisões sobre letrados brasileiros e argentinos. 2015. Dissertação (Mestrado em História Social da Cultura) - Programa de Pós-graduação em História Social da Cultura, Pontifícia Universidade Católica do Rio de Janeiro, Rio de Janeiro, 2015. Disponível em: https://cutt.ly/OxVc3tb. Acesso: 01 abr. 2020.

NICOLAZZI, Fernando. A história e seus passados: regimes historiográficos e escrita da história. In: BENTIVOGLIO, Julio; NASCIMENTO, Bruno (org.). Escrever história: historiadores e historiografia brasileira nos séculos XIX e XX. Serra: Editora Milfontes, 2017. p. 7-36.

NICOLAZZI, Fernando. Orden del tiempo y escritura de la historia: consideraciones sobre el ensayo historico em el Brasil, 1870-1940. Prismas, Revista de historia intelectual, Buenos Aires, n. 19, 2015. Disponível em: https://cutt.ly/TxVcsFl. Acesso em: 03 fev. 2020.

OITICICA, José. Como se deve escrever a história do Brasil. Revista Americana, Rio de Janeiro, ano I, n. 7, p. 109-117, 1910.

OLIVA, Terezinha. Impasses do federalismo brasileiro (Sergipe e a Revolta de Fausto Cardoso). São Paulo: Paz e Terra, 1985.

PEREIRA, Mateus H. F.; SANTOS, Pedro Afonso C.; NICODEMO, Thiago Lima. Uma introdução à história da historiografia brasileira (1870-1970). Rio de Janeiro: Editora da FGV, 2018.

PRADO, Giliard da Silva. Batalhas da memória política em Sergipe: as comemorações das mortes de Fausto Cardoso e Olímpio Campos (1906 - 2006). 2009. Dissertação (Mestrado em História) - Programa de Pós-graduação em História, Universidade Brasília, Distrito Federal, 2009. Disponível em: https://repositorio.unb.br/handle/10482/4060. Acesso em: 04 fev. 2020. 
ROMERO, Sílvio. A América Latina (análise do livro de igual título do Dr. M. Bomfim). Porto: Livraria Chardron, 1906.

ROMERO, Sílvio. História da literatura brasileira. Tomo Primeiro. Rio de Janeiro: H. Garnier; Livreiro-Editor, 1902.

SCHWARCZ, Lilia Moritz. O espetáculo das raças: cientistas, instituições e a questão racial no Brasil - 1870-1930. São Paulo: Companhia das Letras, 2018.

SCHWARZ, Roberto. Um mestre na periferia do capitalismo - Machado de Assis. São Paulo: Duas Cidades, 1990.

VERGARA, Moema. Ciência e literatura: a Revista Brasileira como espaço de vulgarização científica. Sociedade e cultura, Goiânia, v. 7, n. 1, p. 75-88, 2004. Disponível em: https://www.revistas.ufg.br/fcs//article/view/926. Acesso em: 02 fev. 2020.

VERÍSSIMO, José. O modernismo. Revista do Brasil, São Paulo, ano I, v. I, 1916.

WEHLING, Arno. A invenção da História: estudos sobre o historicismo. Rio de Janeiro: EDUFF, 1994.

WEHLING, Arno. Historiografia e epistemologia histórica. In: MALERBA, Jurandir (org.). A história escrita: teoria e história da historiografia. São Paulo: Contexto, 2006. p. 175-189.

\section{INFORMAÇŌES ADICIONAIS}

\section{BIOGRAFIA PROFISSIONAL}

Piero Detoni é doutorando em História Social pela Faculdade de Filosofia, Letras e Ciências Humanas da Universidade de São Paulo (FFLCH/USP). Licenciado, bacharel e mestre em História pela Universidade Federal de Ouro Preto (UFOP). Estuda, atualmente, a experiência historiográfica no IHGB na Primeira República. Autor de É a história uma ciência? (2021).

\section{ENDEREÇO PARA CORRESPONDÊNCIA}

Universidade de São Paulo, FFLCH, Avenida Professor Lineu Prestes, Butantã, n. 2415, São Paulo, SP, CEP 05508-000, Brasil. 
FINANCIAMENTO

Conselho Nacional de Desenvolvimento Científico e Tecnológico (CNPq), processo n. 870225/1997-9.

\section{CONFLITO DE INTERESSE}

Nenhum conflito de interesse declarado.

\section{APROVAÇĀO EM COMITÊ DE ÉTICA}

Não se aplica.

MODALIDADE DE AVALIAÇĀO

Duplo-cega por pares.

\section{EDITORES RESPONSÁVEIS}

Alexandre Avelar - Editor convidado

Breno Mendes - Editor Executivo

Lidiane Soares Rodrigues - Editora convidada

María Inés Mudrovcic - Editora convidada

DIREITOS AUTORAIS

Copyright (c) 2021 Piero Detoni.

\section{LICENÇA}

Este é um artigo distribuído em Acesso Aberto sob os termos da Creative Commons Atribuição 4.0 Internacional.

HISTÓRICO DE AVALIAÇĀO

Recebido em: 23 de julho de 2020.

Alterado em: 2 de abril de 2021.

Aprovado em: 2 de abril de 2021. 